\title{
Um olhar sobre o compartilhamento de equipamentos, em instituições de pesquisa, nas cidades do Rio de Janeiro e São Paulo: principais diferenças, semelhanças e desafios observados
}

\author{
A look at equipment sharing in research institutions in the cities of Rio \\ de Janeiro and Sao Paulo: main differences, similarities and challenges \\ observed
}

\section{Una mirada en el compartir de equipos en las instituciones de investigación en las ciudades de Río de Janeiro y Sao Paulo: principales diferencias, similitudes y desafíos observados}

Maria Beatriz Andrade Fontoura de Carvalho | mbafc1@gmail.com

Fundação Osvaldo Cruz, Instituto Nacional de Saúde da Mulher, da Criança e do Adolescente Fernandes Figueira. Rio de Janeiro, RJ, Brasil.

Andre Luis Gemal | agemal@iq.ufrj.br

Universidade Federal do Rio de Janeiro, Instituto de Química. Rio de Janeiro, RJ, Brasil.

Katia Christina Leandro | katia.leandro@incqs.fiocruz.br

Fundação Osvaldo Cruz, Instituto Nacional de Controle de Qualidade em Saúde. Rio de Janeiro, RJ, Brasil.

\section{Resumo}

As últimas décadas foram marcadas por mudanças no cenário da pesquisa evidenciadas pela formação de redes de colaboração e, também, maior interação da área acadêmica e o setor produtivo. Nesse contexto, emergiram novos arranjos estruturais, como por exemplo, o compartilhamento de equipamentos em laboratórios de pesquisa e desenvolvimento tecnológico, identificados como multiusuários, core facilities, central analítica ou plataformas tecnológicas. O objetivo deste trabalho é conhecer o compartilhamento de equipamentos existentes em uma instituição de pesquisa nacional no Rio de Janeiro, comparativamente a outras instituições com perfil e grau semelhante de reconhecimento em São Paulo. Foram avaliadas unidades de instituições públicas. Apesar das semelhanças dos processos característicos à vinculação institucional e das dificuldades enfrentadas, advindas dos mecanismos da administração pública, existem diferenças no gerenciamento encontrado.

Palavras chave: Compartilhamento de equipamentos; equipamentos multiusuários; plataformas tecnológicas; core facilities; central analítica; gerenciamento de facilidades. 


\begin{abstract}
The last few decades have been marked by changes in the research scenario evidenced by the formation of collaborative networks and also more interaction in academia and industry. In this context emerged new structural arrangements such as sharing equipment in technological research and development laboratories identified as multi-user, core facilities and technology platforms. The aim of this study was to know about the sharing of equipment within those structures at an institution of national research in Rio de Janeiro and compare it to other institutions with similar degree of recognition in São Paulo by checking similarities, problems, challenges, operations and management. Units of public institutions were evaluated and it was observed that despite the similarities of the characteristic main processes and the institutional difficulties faced by the public administration mechanisms it was found differences in the facilities management.
\end{abstract}

Keywords: Equipment sharing; multi-user equipments; core facilities; technology platforms; analytical central; facilities management.

\title{
Resumen
}

Las últimas décadas han estado marcadas por los cambios en el panorama de la investigación evidenciadas por la formación de redes de colaboración, así como una mayor interacción entre la academia y el sector productivo. En este contexto, surgieron nuevos arreglos estructurales, tales como el uso compartido de equipos en laboratorios de investigación y desarrollo tecnológico identificado como multiusuario, instalaciones básicas, o las plataformas centrales de tecnología de análisis. El objetivo de este estudio es conocer la distribución de los equipos existentes en una institución nacional de investigación en Río de Janeiro en comparación con otras instituciones con el perfil y el grado de reconocimiento similar. Unidades de instituciones públicas fueron evaluadas y se observó que a pesar de las similitudes de los procesos característicos de la afiliación institucional y las dificultades que surjan de los mecanismos de la administración pública existen diferencias encontradas en la gestión.

Palabras clave: Reparto de equipos; equipos multi-usuario; plataformas tecnológicas; instalaciones analíticas centrales; gestion de las instalaciones.

Contribuição dos autores:

Concepção e desenho do estudo: Maria Beatriz Andrade Fontoura de Carvalho e Andre Luis Gemal Aquisição, análise ou interpretação dos dados: Maria Beatriz Andrade Fontoura de Carvalho

Redação do manuscrito: Maria Beatriz Andrade Fontoura de Carvalho

Revisão crítica do conteúdo intelectual: Andre Luis Gemal e Katia Christina Leandro

Declaração de conflito de interesses: Não

Fontes de financiamentos: Não

Agradecimento/Contribuições adicionais: A todos os pesquisadores, gerentes e coordenadores das Unidades do Rio de Janeiro e São Paulo que contribuíram, viabilizando a conclusão deste trabalho.

Apresentação anterior: Dissertação de mestrado defendida por Carvalho, M.B.A.F.

Histórico do artigo: Submetido: 15.ago.2015 | Aceito: 19.maio.2016 | Publicado: 30.jun.2016.

Licença CC BY-NC atribuição não comercial. Com essa licença é permitido acessar, baixar (download), copiar, imprimir, compartilhar, reutilizar e distribuir os artigos, desde que para uso não comercial e com a citação da fonte, conferindo os devidos créditos de autoria e menção à Reciis. Nesses casos, nenhuma permissão é necessária por parte dos autores ou dos editores. 


\section{Introdução}

As últimas décadas foram marcadas por profundas mudanças no campo científico e tecnológico. Novas estruturas organizacionais, estilos de administração e estratégias de desenvolvimento substituíram as vigentes buscando atender a nova dinâmica científica e às exigências do mundo globalizado ${ }^{1,2}$. Um novo estilo de organização e comunicação emergiu com a revolução da tecnologia da informação: a formação de redes ${ }^{3}$. Na nova era, estas passaram a constituir a nova morfologia social da sociedade. Modificaram de forma substancial tanto a conexão entre os indivíduos como os processos produtivos consagrando-se, num arranjo comum, para o estabelecimento das parcerias externas e relacionamentos ${ }^{3}$. Floresceu na pesquisa com o crescimento da formação de redes cola-

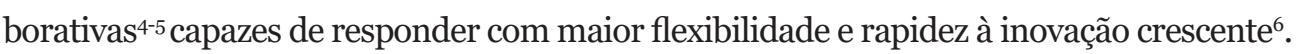

Esta mudança de paradigma apresentou inúmeros desafios institucionais ${ }^{7-9}$, e para este enfrentamento houve necessidade, para além de uma mudança cultural, da adoção de novas práticas de gestão. As redes de colaboração formadas e os novos arranjos estruturais que emergiram, como, por exemplo, o compartilha-

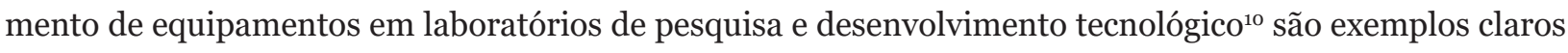
desta situação e da necessidade de novas práticas de coordenação inter e intra organizacionais.

A colaboração entre os grupos de pesquisa, motivada por diversos fatores ${ }^{4}$, se consolidou, em grande parte, devido ao alto custo de equipamentos, que por sua vez dificultou o financiamento de grupos isolados $^{5}$. As associações de pesquisadores, com o intuito de aperfeiçoar a relação custo-benefício, proveniente do compartilhamento dos recursos ${ }^{11}$ foi privilegiada pelas agências financiadoras. Como exemplo, o desenvolvimento da biotecnologia, em particular, envolveu a colaboração de pesquisadores das disciplinas tradicionais, e também a universidade, centros tecnológicos e indústrias ${ }^{5}$, possibilitando a formação de grupos provenientes do compartilhamento de competências e equipamentos complexos ${ }^{12}$. Esta situação vem se repetindo com a nanociência.

\section{A emergência dos arranjos de compartilhamento de equipamentos}

O desenvolvimento e incorporação de novas técnicas analíticas, o alto grau de automação ${ }^{13} \mathrm{e}$ integração dos equipamentos aliados à melhoria dos sistemas de aquisição de dados culminaram com o desenvolvimento de estruturas complexas de medição, maior rapidez, maior sensibilidade e mais eficiência. O lançamento de novas versões de equipamentos, no mercado, com características inovadoras e em intervalos menores acelerou a obsolescência, diminuindo o seu ciclo de vida ${ }^{14-15}$. Um aumento expressivo de investimento financeiro e na estrutura física para o aparelhamento de um laboratório analítico individual com o nível de especialização necessário ${ }^{16-17}$ representou o fator limitante ao usufruto das vantagens associadas à utilização de novas técnicas ${ }^{16-18}$. Assim, o surgimento de estruturas centralizadas e o compartilhamento associado possibilitaram o acesso ampliado a estes novos equipamentos complexos ${ }^{19}$. Inúmeras novas denominações passaram a ser usadas ${ }^{5,20}$ quando equipamentos eram disponibilizados em uma infraestrutura central em conjunto ou não com pessoal capacitado para operação e suporte de serviços ${ }^{16,21}$. Centrais analíticas e plataformas tecnológicas, por exemplo, para uma configuração de equipamentos e pessoas alinhadas a programas e agendas estratégicas ${ }^{1}$, ou simplesmente equipamentos multiusuários quando uma instituição decide comprar um único equipamento para ser utilizado por dois ou mais laboratórios ${ }^{22}$. O impacto científico obtido a partir destes novos arranjos foi destacado por Coulter $^{23}$, Zolotov ${ }^{24}$, e durante o final do século 20, vários campos da ciência foram beneficiados, ao se considerar o desenvolvimento e acesso a equipamentos complexos e seus diferentes padrões de uso $^{25-26}$.

Num sentido mais abrangente, esse processo consolidou locais de hibridização de tecnologias e encontro de pesquisadores ${ }^{19-27}$ representando várias disciplinas, organizações e posições hierárquicas. Culminaram no crescimento de comunidades científicas e desenvolvimento de novas competências ao redor de um 
equipamento ${ }^{28}$. Alinhados a um ambiente favorável à aceleração da inovação, estes espaços ${ }^{29} \operatorname{contribuíram~}$ fortemente para a cooperação e transferência de conhecimento ${ }^{30-31}$, e se caracterizaram como um verdadeiro foco do progresso tecnológico, despertando o interesse de vários setores.

Apesar do reconhecimento pela comunidade científica do papel essencial representado pela criação das plataformas tecnológicas, em geral, no avanço da ciência e produção de conhecimento, vários são os desafios constantemente enfrentados pelos seus gerentes organizacionais no que se refere à busca de soluções

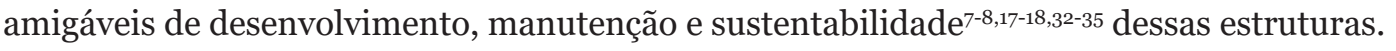

\section{Gerenciamento e desafios das facilidades e plataformas tecnológicas}

Na gestão moderna, muitos métodos podem ser aplicados para melhorar os resultados de desempenho ${ }^{36}$, aperfeiçoar processos organizacionais, alcançar níveis mais eficientes e eficazes na utilização de recursos e, num sentido ampliado, garantir a sustentabilidade e sobrevivência das organizações, independentemente de sua natureza ${ }^{37}$. Nesse sentido, a criação das facilidades (facilities ${ }^{i, i i}$ ) na sua concepção, já se constituiu um movimento inicial em direção a uma maior eficiência e eficácia associadas à economia de escala ${ }^{8}$. No entanto, restam simplificadamente os problemas relacionados aos fatores básicos na operação dos equipamentos, como a aquisição dos insumos necessários para a realização da técnica, a necessidade de reposição de peças para reparos eventuais, os contratos de manutenção com os fabricantes ou representantes ${ }^{18,31,41}$ e a garantia de validação do processo e certificação de acordo com o sistema da qualidade. Em relação à gestão de pessoal, também pode indicar uma proposta de maior eficiência relativa a salários e benefícios para a equipe técnica orientada aos serviços disponibilizados ${ }^{8}$. Entretanto, pesquisadores e instituições são constantemente desafiados a encontrar práticas de gestão mais eficientes ${ }^{17} \mathrm{e}$ adequadas às necessidades específicas, operacionais, culturais e históricas mantendo o foco nas questões mais estratégicas ${ }^{18}$, buscando atender a legislação em vigor.

Outra importante constatação é que poucos gerentes têm algum treinamento formal em aspectos administrativos ${ }^{7} \mathrm{e}$ as facilidades se desenvolveram sem um planejamento geral, em parte devido à natureza do financiamento voltado a projetos únicos ou focados em uma única doença ou agravo. Na prática, verifica-se que para um gerenciamento mais efetivo, é desejável que os envolvidos tenham experiência adicional em técnicas de gestão de projetos e considerável habilidade na comunicação interpessoal ${ }^{36}$. Muitos já consideram a adoção de um plano de negócios revisado anualmente com cumprimento de metas estabelecidas, adequação ao orçamento projetado e monitoramento de despesas e receitas ${ }^{33}$. Haley ${ }^{18}$ propôs a elaboração de uma diretriz para facilitar as discussões sobre o gerenciamento estratégico das facilidades. Em sua abordagem, quatro áreas inter-relacionadas são consideradas como principais desafios e oportunidades na implantação de qualquer prática de gestão estratégica. Na primeira, a visão e visibilidade das facilidades construídas dentro da instituição são apontadas como condição estratégica básica. Englobam questões relacionadas à disponibilidade da infraestrutura necessária na instituição, comprometimento, financiamento e cultura de compartilhamento institucional; em seguida, a operação e gerenciamento são considerados a base do funcionamento das facilidades e abarcam a necessidade de desenvolvimento de um modelo de negócio, estabelecimento de políticas institucionais de serviço e procedimentos de governança operacionais e de gestão. Outro destaque é a análise e avaliação continuada das estruturas, objetivando melhorar suas operações através de modelos de gerenciamento mais efetivos. E finalmente, o aperfeiçoamento dos me-

\footnotetext{
i A premissa básica de compartilhamento de equipamentos gira em torno de sua utilização por múltiplos usuários. Vários autores conceituaram e exemplificaram as construções destas estruturas, cujos enfoques foram estabelecidos de acordo com os campos da ciência associados ou perspectivas envolvidas.

ii As estruturas descritas até então serão referenciadas como facilidades, porém as abordagens descritas englobam tanto as core facilities quanto as plataformas tecnológicas e centrais analíticas.
} 
canismos de tomada de decisão e investimentos nas facilidades que auxiliem as questões já referenciadas quanto a sua operação e estratégia.

Assim o modelo proposto por Haley ${ }^{18}$ foi baseado na análise de várias instituições com o objetivo de resolver questões julgadas por seus administradores como de alto impacto e de grande pressão. Outro modelo, considerado por Lilley ${ }^{24}$, são os desafios diários e as necessidades não satisfeitas relatadas em relação às facilidades, mas que podem ser consideradas como problemas verificados em muitos laboratórios de pesquisa e se referem aos cuidados com as amostras, a aquisição, manutenção e substituição de equipamentos, a atualização da tecnologia, a gestão de pessoas e o financiamento em geral.

Esse trabalho foi motivado pela necessidade de encontrar um modelo de compartilhamento de equipamentos recentemente adquiridos, em uma determinada instituição de pesquisa. Partiu da constatação da inexistência da mesma e da dificuldade relatada, por diversos pesquisadores, de como efetivar na cultura daquela instituição esta nova forma de trabalho. Dentro desta perspectiva, este estudo objetivou conhecer os aspectos diversos de compartilhamento dos equipamentos de acordo com parâmetros descritos na literatura. Assim, o objeto de estudo foi uma instituição de pesquisa nacional, com unidades na cidade do Rio de Janeiro e comparativamente com outras instituições com grau semelhante de reconhecimento e perfil de atuação na cidade de São Paulo.

\section{Metodologia}

A metodologia deste estudo compreendeu as seguintes etapas: levantamento e seleção dos locais considerados adequados ao escopo do estudo, com base em avaliações de produtividade e capacitação tecnológica no meio acadêmico. Posteriormente, foi iniciada a coleta e análise dos dados. Para tal, utilizouse a metodologia denominada de análise de conteúdo, segundo Bardin ${ }^{38}$. A condução da análise de dados obtidos abrangeu as seguintes fases:

1. Pré-análise, que constituiu a fase de organização e sistematização dos conteúdos;

2. Exploração do material, fase de categorização dos dados objetivando facilitar a organização e compreensão do material para posterior codificação;

3. Tratamento dos resultados e interpretação.

Como proposta de estudo preliminar, não foi definida uma amostragem nacional, e sim a sistematização da situação em unidades locais específicas, em instituições de alta produtividade científica e reconhecimento acadêmico. Para tal, foram selecionados, nas cidades do Rio de Janeiro e São Paulo, 21 locais considerados adequados ao escopo do estudo por expressarem o perfil de compartilhamento de equipamentos com o mesmo grau de complexidade, caracterizados como multiusuários nas expressões utilizadas pela literatura internacional (core facilities, centrais analíticas e plataformas tecnológicas). Para a coleta dos dados foi realizada pesquisa qualitativa nos locais escolhidos, constituídas por entrevistas individuais, devido ao caráter exploratório do estudo e a diversidade de locais que constituíram a amostragem. O roteiro das entrevistas foi baseado nos tópicos temáticos de maior relevância encontrados no referencial teórico.

Os entrevistados foram pesquisadores, coordenadores e operadores dos equipamentos, bolsistas de doutorado ou pós-doutorado que concordaram prontamente em participar. As entrevistas, realizadas entre janeiro e setembro de 2013, foram gravadas, e, posteriormente, transcritas para então serem verificadas segundo a análise de conteúdo ${ }^{38}$.

A escolha desta técnica de análise se deu em função da necessidade de compreender os depoimentos de entrevistados provenientes de lugares diversos preservando a liberdade de expressão pessoal, e ao mesmo tempo realizar de forma eficiente uma análise comparativa das diferentes falas. Para tal, os depoimentos transcritos foram agrupados em duas listas distintas referentes a São Paulo e Rio de Janeiro, de forma a 
se obter o corpus de análise necessário às etapas de codificação e categorização preconizadas por Bardin ${ }^{38}$. Para a codificação foi utilizada uma frase do depoimento como unidade de registro ${ }^{38}$ que, dentro da unidade de contexto ${ }^{38}$, fosse de interesse para os objetivos do trabalho. As unidades de contexto foram os temas definidos e explorados nas entrevistas. Para a fase de categorização, foram identificadas as reais categorias de interesse e delimitadas suas abrangências. As categorias a posterior utilizadas foram as mesmas identificadas inicialmente e foram construídas a partir de tópicos julgados significativos para o estudo. O objetivo desta construção foi buscar identificar elementos relevantes, recorrentes e aspectos semelhantes e divergentes entre os locais. A partir dos resultados obtidos, foram analisadas as semelhanças, problemas e desafios na sua operacionalização.

\section{Construção dos tópicos temáticos}

Para o embasamento dos requisitos analisados neste estudo, foram contextualizados tópicos temáticos descritos no Quadro 1 que englobaram as principais abordagens acima descritas encontradas na literatura. Esta construção permitiu uma boa noção do funcionamento, da amplitude dos problemas e desafios encontrados e que constituíram as diretrizes para a criação de categorias posteriores abordadas tanto na verificação como na discussão dos resultados.

\section{Quadro 1. Consolidação dos tópicos temáticos}

\begin{tabular}{|c|}
\hline Equi \\
\hline $\begin{array}{l}\text { Considerável aporte financeiro para garantia da competitividade. Aquisição e substituição de equipamentos } \\
\text { considerados no estado da arte. Garantir sua operação com inclusão no planejamento e orçamento institucional }{ }^{36,39} \text {. }\end{array}$ \\
\hline $\begin{array}{l}\text { Acompanhar a evolução tecnológica devido à rápida obsolescência e subutilização dos equipamentos podendo } \\
\text { culminar com o fechamento das facilidades }{ }^{16} \text {. }\end{array}$ \\
\hline $\begin{array}{l}\text { Atualizar novas tecnologias para garantir a sobrevivência e oferta de novos serviços e novas técnicas na rotina da } \\
\text { instituição }{ }^{33} \text {. }\end{array}$ \\
\hline $\begin{array}{l}\text { Reconsiderar equipamentos obtidos por pesquisadores através de recursos próprios não compartilhados e que } \\
\text { podem resultar em custos adicionais de manutenção não orçados anteriormente }{ }^{8} \text {. }\end{array}$ \\
\hline Apostar em um modelo centralizado evitando duplicações de equipamentos para melhor efetividade ${ }^{17}$. \\
\hline $\begin{array}{l}\text { Garantir um tempo de inatividade mínimo através de contratos de serviços completos de manutenção, } \\
\text { considerados caros e fora do alcance de muitas instalações }{ }^{33} \text {. }\end{array}$ \\
\hline $\begin{array}{l}\text { Manter os equipamentos em boas condições de funcionamento é um dos principais desafios. Instrumentos } \\
\text { parados, de alto rendimento, significam filas longas, pressão dos usuários e custos inerentes a inatividade }{ }^{37} \text {. }\end{array}$ \\
\hline Usuários \\
\hline $\begin{array}{l}\text { A conquista de novos usuários está diretamente relacionada a melhor divulgação e aumento da visibildade dentro } \\
\text { da própria instituição. Ações focadas em marketing fora da instituição, especialmente a oferta de serviços para a } \\
\text { indústria como forma de também incrementar sua receita operacional }{ }^{8} \text {. }\end{array}$ \\
\hline Os usuários externos, de empresas, podem ser cobrados com taxas significativamente mais elevadas ${ }^{8}$. \\
\hline $\begin{array}{l}\text { Os usuários externos constituem uma grande oportunidade potencial de serviços. Foram propostas ações a serem } \\
\text { desenvolvidas, como as boas práticas de gestão, focando a melhoria do relacionamento com seus usuários }{ }^{9} \text {. }\end{array}$ \\
\hline $\begin{array}{l}\text { Aumentar a divulgação das tecnologias mais avançadas, encorajando os pesquisadores novatos a usá-las em suas } \\
\text { pesquisas. Promover a cobrança de taxas reduzidas com o objetivo de aumentar a produtividade }{ }^{16} \text {. }\end{array}$ \\
\hline $\begin{array}{l}\text { Equipamentos que não estão em uso devem ser disponibilizados para outros usuários mediante ao pagamento de } \\
\text { taxa de serviço, gerando recursos que irão para contas de pesquisa. Este fato dará maior agilidade e flexibilidade } \\
\text { para a gestão e, simultaneamente, a minimização da inatividade do equipamento }{ }^{20} \text {. }\end{array}$ \\
\hline Recursos Humanos \\
\hline $\begin{array}{l}\text { A disponibilização de pessoal altamente capacitado e especializado é intrínseca à concepção das facilidades. } \\
\text { A motivação e retenção do pessoal não devem ser subestimadas. Para seu funcionamento pleno, deve-se ter } \\
\text { como estratégia fixar pessoal qualificado. Adicionalmente, é apontado que um gerente não quer trocar e treinar } \\
\text { continuamente novos colegas de trabalho33. }\end{array}$ \\
\hline
\end{tabular}


A perda de mão de obra para outra organização depois de alguns anos de contrato, os custos envolvidos para a substituição e todo o investimento realizado sendo perdido é um problema recorrente $\mathrm{e}^{27-19}$.

\section{Recursos Humanos (continuação)}

Outro fator impactante se refere ao recrutamento de pessoal e a oferta de salários e benefícios. Devem ser compatíveis com o alto nível de competência científica desejado ${ }^{35,42}$.

Promover constantemente o conhecimento e capacitação necessária para operação das novas tecnologias, incluindo treinamentos das tecnologias ofertadas em programas de graduação e pós-graduação. Manter uma forma de capacitação e atualização de pessoal técnico ${ }^{35}$.

Como consequência direta ao não atendimento da capacitação necessária, os laboratórios podem tornar-se obsoletos em poucos anos ${ }^{16}$.

A falta de políticas referentes à progressão funcional e descrição das capacitações técnicas em algumas instituições pode se constituir um problema ${ }^{17}$.

Na pesquisa colaborativa, maior importância deve ser dada ao gerenciamento de pessoas e ao alinhamento de suas competências e habilidades para trabalhar em equipes, especialmente quando o desempenho exigido inclui múltiplas habilidades, a capacidade de julgamento e experiências diversas ${ }^{23}$.

\section{Financiamento}

Basicamente realizado com o orçamento anual da instituição ou parte do custo com verbas de pesquisa individual ${ }^{16}$.

Várias fontes e possibilidades de financiamento utilizadas são reportados em uma pesquisa com seus gerentes ${ }^{40}$.

Corte de financiamento nos últimos anos e escassez de recursos financeiros estão na pauta das discussões quando são consideradas questões de gerenciamento e enfrentamento de tempos de turbulência econômica. É consenso a adoção de novos modelos de gestão ${ }^{8}$.

Criação de um plano de negócios deve futuramente orientar as tomadas de decisão das instituições na busca de melhor controle das despesas e um gerenciamento mais eficiente das instalações ${ }^{17,24}$.

\section{Cobrança de taxas}

Muitas instituições e políticas de financiamento recomendam a cobrança de taxa de serviços. Tema destacado por se constituir uma fonte de receita que permite equilibrar alguns custos de rotina com mais eficácia ${ }^{16}$.

Para cobrir o seu custo direto, a maioria das facilidades opera com a receita proveniente da recuperação de taxas de serviço cobradas, mas mesmo assim dependem do suporte institucional para cobertura dos custos indiretos, relacionados à infraestrutura, aquisição de novos equipamentos e manutenção. O modelo atual de financiamento é apontado como insustentável na economia atual e uma das maiores preocupações entre os administradores é saber como enfrentarão as dificuldades de financiamento durante os tempos difíceis de crise econômica ${ }^{8}$.

Muitas instituições estão procurando clientes no setor privado, com a perspectiva de colaboração e auxílio na manutenção.

Os gerentes raramente conhecem completamente seus custos totais e reais de operação?.

Busca de fontes alternativas de financiamento na luta pela sua sustentabilidade, oferecimento de seus serviços aos setores privados. Taxas não devem constituir um fator de discriminação de usuários e incentivo a novas oportunidades científicas em virtude de altos valores cobrados. Cobertura de custos de salários, consumíveis e manutenção de equipamentos com a receita obtida através da cobrança de taxa. Administradores incentivam a recuperação através desta cobrança.

Se a expectativa é ser autossustentável com $100 \%$ da cobertura de sua despesa, ela deverá ser consideravelmente produtiva para gerar tal recurso.

Existe uma grande diferença entre as taxas cobradas por diferentes facilidades nas universidades para o mesmo serviço. Os fatores que podem contribuir para estas diferenças são representados pela diferença de recursos orçamentários disponíveis, tempo gasto em operações não produtivas como manutenção, e calibração. 0 desenvolvimento de técnicas e serviços, que não são pagos, e não revertem em receitas podem contribuir para este fato. Dados de campo mostram que existe muito improviso em relação ao cálculo de custos e também sua alocação para o cálculo de valores de taxas diferenciadas ${ }^{35}$.

Na grande maioria das instituições, as taxas de utilização dos equipamentos são inevitáveis, porém a recomendação é que não devem constituir um fator de discriminação de usuários ${ }^{39}$.

Algumas instituições já operam com diretrizes estabelecidas para cobrança de taxa e administração desses recursos. Adotaram modelos de centros de custos operados por um Escritório de Pesquisa que oferecem mecanismos mais eficientes para a recuperação dos custos diretos associados ao fornecimento desses serviços. A receita das taxas dos usuários é revertida diretamente para um fundo do pesquisador ${ }^{41}$ ou da facilidade. 


\section{Resultados e Discussão}

Neste artigo, serão considerados para discussão e apresentação dos resultados os dados obtidos referentes às categorias Equipamentos, Usuários, Recursos Humanos, Financiamento e Cobrança de taxas. Os resultados estão categorizados e serão apresentados inicialmente, os pontos comuns encontrados para as Unidades do Rio de Janeiro ou São Paulo. Os resultados específicos para as Unidades do Rio de Janeiro ou São Paulo, serão apresentados como um consolidado, no Quadro 2.

\section{Consolidação dos pontos comuns encontrados para as Unidades do Rio de Janeiro ou São Paulo}

\section{Equipamentos: esta categoria procurou analisar a aquisição e manutenção dos equipamentos}

No que se refere à aquisição de equipamentos, pode ser evidenciado que a origem dos recursos utilizados é semelhante. Obtidos a partir de programas de equipamentos multiusuários editados pelas principais agências públicas de fomento, através de projetos individuais ou por um conjunto de pesquisadores.

Alguns equipamentos são adquiridos (embora mais raramente) com recursos orçamentários das instituições, mas com o custo de equipamentos complexos girando em torno de milhões de dólares e orçamentos limitados. Pode ser observada, mesmo nesses casos, a necessidade de associação de um ou mais pesquisadores locais para viabilizar a aquisição de um único equipamento. Esta aglutinação pode ser fortalecida pela crescente preocupação com a chamada produtividade científica, medida pelo número de publicações.

Destacou-se aqui a aquisição de equipamentos muito caros, alguns inovadores e únicos e a grande especialização do parque tecnológico das instituições pesquisadas, comparável às instituições internacionais. A busca de atualização e adequação à tecnologia de ponta e oferta de novas tecnologias é claramente um esforço comum entre agências, pesquisadores e instituições.

Com relação à manutenção de equipamentos, verifica-se praticamente inexistência de contratos de manutenção. Alguns laboratórios reservam verbas para realização do serviço, quando necessário. Também foi evidenciada uma tendência de elaboração de editais de compra programando a garantia estendida de manutenção. Outro ponto é a vantagem de preço obtida pelas unidades que negociam contratos de manutenção em conjunto.

\section{Recursos humanos}

Esta categoria procurou analisar quem opera os equipamentos, formação, vínculo institucional, capacitação necessária.

Recursos humanos é um dos pontos críticos observados, e foi potencializado por se tratar de instituições públicas e suas limitações práticas de contratação.

Adicionalmente, foram relatados como requisitos básicos neste tópico a necessidade de um tempo elevado para a formação de pessoal, alinhamento das habilidades pessoais às atividades realizadas, disponibilização de capacitação e promoção de conhecimento através de programas de ensino e, finalizando, motivação e comprometimento dos operadores dos equipamentos. 


\section{Clientes}

Essa categoria procurou conhecer a base de usuários que utiliza os equipamentos.

A base de atendimento é representada, em sua maioria, por usuários da própria unidade onde está localizado o equipamento. Em seguida, são atendidos usuários de outras unidades dentro da instituição, de universidades locais e também de outros Estados.

\section{Recursos financeiros}

Essa categoria procurou conhecer o tipo de financiamento existente e a cobrança de taxas de serviço.

Conforme já assinalado, os mesmos mecanismos são utilizados pelas instituições do Rio e São Paulo, em geral constituídos por verbas do orçamento institucional e de projetos individuais e coletivos.

Destaca-se nesse ponto a receita obtida a partir da cobrança de taxas. Consideradas em alguns modelos de compartilhamento como subsídio das suas principais operações e adotadas como diretrizes em alguns escritórios centrais de projetos.

Na prática, muitas instituições vêm cobrindo parte de seus custos diretos através desta receita ${ }^{34-36}$. Embora os resultados não evidenciem um aumento significativo no número de unidades autossustentáveis ao longo do tempo, a maioria utiliza este mecanismo de cobrança como meio de gerenciar parte de seus custos.

Os custos diretos estão associados na maioria das pesquisas à execução e operação e incluem salários do pessoal, consumíveis e contratos de serviços para equipamentos.

Esta fonte de recursos, porém, não é prática comum nas unidades do Rio de Janeiro, mas é realizada nas unidades de São Paulo.

No quadro abaixo, estão apresentadas esta e outras diferenças encontradas entre estas unidades.

Quadro 2. Consolidação dos resultados específicos encontrados para as Unidades do Rio de Janeiro ou São Paulo

\begin{tabular}{|l|}
\hline Equipamentos: esta categoria procurou analisar a aquisição e manutenção dos equipamentos \\
\hline Rio de Janeiro \\
\hline Equipamentos, em geral, sem contratos ou sem a realização de manutenção preventiva. \\
\hline São Paulo \\
\hline $\begin{array}{l}\text { O cumprimento dos programas de manutenção prolongou a vida dos equipamentos que passam a ser trocados } \\
\text { somente por obsolescência. }\end{array}$ \\
\hline $\begin{array}{l}\text { O conhecimento do funcionamento e treinamento com o fabricante podem resolver pequenos problemas evitando } \\
\text { transtornos com equipamento parado. }\end{array}$ \\
\hline $\begin{array}{l}\text { Avaliar a melhor forma de estabelecimento dos programas de manutenção e necessidade de contratos, podendo } \\
\text { ser caracterizados por cobrança de horas e economizar recursos. }\end{array}$ \\
\hline Conhecimento do pós-venda do fabricante na escolha dos equipamentos e estabelecimento de parcerias. \\
\hline Habilidade na negociação e avaliação de prioridades no estabelecimento de contratos. \\
\hline
\end{tabular}




\begin{tabular}{|c|}
\hline $\begin{array}{l}\text { Recursos humanos: esta categoria procurou analisar quem opera os equipamentos, formação, } \\
\text { vinculo institucional, capacitação necessária. }\end{array}$ \\
\hline Rio de Janeiro \\
\hline Maior parte dos operadores constituída por bolsistas de doutorado, pós-doutorado (alunos de pós-graduação). \\
\hline Alto nível profissional desejado para a operação dos equipamentos e grande vulnerabilidade na continuidade do serviço. \\
\hline A vinculação dos operadores às bolsas de estudo dificulta a retenção de muitos talentos. \\
\hline O valor das bolsas dificulta a contratação de pessoas com a qualificação necessária. \\
\hline Gerentes menos preocupados quando contam com servidores por caracterizarem vínculos mais estáveis. \\
\hline Perda de pessoal treinado para outros locais com ofertas melhores após grande esforço e tempo de treinamento. \\
\hline $\begin{array}{l}\text { Bolsistas que operam os equipamentos devem dividir seu tempo com a pesquisa individual, o que impacta na } \\
\text { disponibilidade dos horários do equipamento. }\end{array}$ \\
\hline São Paulo \\
\hline $\begin{array}{l}\text { Liberação de equipamentos obtidos por programas multiusuários somente após a constatação pela agência de } \\
\text { fomento de pessoal capacitado disponível para sua operação. }\end{array}$ \\
\hline Busca de soluções através da contratação para facilitar a fixação e a capacitação. \\
\hline $\begin{array}{l}\text { Oferta aos colaboradores dos seus laboratórios de benefícios equiparados aos da iniciativa privada, resolvendo em } \\
\text { parte o problema da retenção e motivação de pessoal. }\end{array}$ \\
\hline $\begin{array}{l}\text { Possibilidade de estabelecimento de vínculos trabalhistas mais atrativos, em parte pela autossustentabilidade } \\
\text { obtida através da cobrança de taxas. }\end{array}$ \\
\hline A cobrança de taxas possibilitou a oferta de assistência médica, vale-refeição e cesta básica. \\
\hline Clientes: essa categoria procurou conhecer a base de usuários que utiliza os equipamentos \\
\hline Rio de Janeiro \\
\hline $\begin{array}{l}\text { O número de atendimentos é maior dentro do próprio departamento, depois na Unidade e por último em outras } \\
\text { unidades do Rio de Janeiro e outros Estados. }\end{array}$ \\
\hline $\begin{array}{l}\text { Inexistência de relatórios gerenciais que permitam melhor conhecimento do perfil de usuários e a porcentagem } \\
\text { representada por cada segmento de usuário. }\end{array}$ \\
\hline $\begin{array}{l}\text { Inexistência de parcerias com a indústria, apesar de haver interesse de alguns setores industriais por não existirem } \\
\text { formas de cobrança de serviços que revertam recursos ao laboratório. }\end{array}$ \\
\hline Não foi evidenciado o atendimento a usuários corporativos. \\
\hline $\begin{array}{l}\text { Existe compartilhamento dos equipamentos de alto custo de um laboratório com usuários de outra Rede do Rio de } \\
\text { Janeiro e também com outro Instituto Tecnológico de Pesquisa fora da instituição. }\end{array}$ \\
\hline São Paulo \\
\hline Atendimento a usuários corporativos. \\
\hline Existência de interação e bom relacionamento com a indústria. \\
\hline Cobrança de taxas \\
\hline Rio de Janeiro \\
\hline Não foi constatada a cobrança de taxas de serviços. \\
\hline Existe um desconhecimento da possibilidade e mecanismos de cobrança de taxas que tragam benefícios. \\
\hline Concordância de boa parte dos pesquisadores para a cobrança, mas nunca pensaram na questão. \\
\hline Não é considerada como atividade de um pesquisador o gerenciamento de taxas e funções administrativas. \\
\hline $\begin{array}{l}\text { O tempo despendido para estas funções é considerado como tempo perdido, o que implica em menos pesquisas e } \\
\text { publicações. }\end{array}$ \\
\hline Concordância com outras formas de cobrança pelo uso dos equipamentos como através de insumos ou colaboração. \\
\hline Descrença na execução de mecanismos de gerenciamento do dinheiro arrecadado por taxas. \\
\hline $\begin{array}{l}\text { Concordância com a cobrança como receita alternativa capaz de melhorar o gerenciamento e comprar peças e } \\
\text { insumos com rapidez. }\end{array}$ \\
\hline O sistema existente que poderia ser utilizado não retorna valores diretamente aos laboratórios. \\
\hline Desconhecimento para lidar com a questão, mas que poderia se constituir numa possível solução. \\
\hline Não concordância de alguns com a cobrança de taxas pelo caráter científico da pesquisa. \\
\hline $\begin{array}{l}\text { Poderia existir mecanismo alternativo de cobrança para gerenciar melhor os insumos e manter os equipamentos } \\
\text { funcionando. }\end{array}$ \\
\hline
\end{tabular}




\begin{tabular}{|c|}
\hline São Paulo \\
\hline $\begin{array}{l}\text { Todos adotaram a cobrança de taxas, com exceção de um laboratório multiusuário somente para uso acadêmico de } \\
\text { alunos e professores. }\end{array}$ \\
\hline Existência de locais autossustentáveis que gerenciam muitos problemas pontuais a partir deste recurso. \\
\hline $\begin{array}{l}\text { Incentivo de agência de fomento para a busca da autosustentabilidade para eliminar o financiamento de contratos } \\
\text { de manutenção e despesas de custeio através de editais. }\end{array}$ \\
\hline Existência de mecanismos claros de cobrança. \\
\hline $\begin{array}{l}\text { Operação de laboratórios de pesquisa como negócio pode ser considerada por muitos como falta de visão } \\
\text { intelectual e científica. }\end{array}$ \\
\hline Desafios e problemas \\
\hline Rio de Janeiro \\
\hline A fragilidade do vínculo empregatício enfatiza o "ciclo vicioso" que se tornou o treinamento e a perda de pessoal. \\
\hline Impossibilidade de retenção de bolsistas comprometendo a consolidação das estruturas. \\
\hline Inexistência de planos de carreira e benefícios ofertados aos bolsistas. \\
\hline Falta de motivação, portanto o discurso mais comum é "quando arrumam algo melhor não tem por que continuar". \\
\hline Grande expectativa de se obter uma vaga em futuros concursos como forma de prover operadores fixos. \\
\hline Falta de eficácia institucional na execução dos procedimentos públicos. \\
\hline Alguns pesquisadores usam verbas disponíveis de seus projetos pessoais para gastos emergenciais. \\
\hline $\begin{array}{l}\text { Problemas recorrentes de equipamentos quebrados de grande relevância para a pesquisa e interrupção do } \\
\text { funcionamento do laboratório. }\end{array}$ \\
\hline $\begin{array}{l}\text { Grande impacto negativo para a continuidade dos trabalhos acadêmicos e da pesquisa com a impossibilidade de } \\
\text { uso dos equipamentos por quebra. }\end{array}$ \\
\hline $\begin{array}{l}\text { Grande expectativa em relação à obtenção de um contrato institucional de manutenção que venha a resolver os } \\
\text { transtornos frequentes com seus equipamentos. }\end{array}$ \\
\hline
\end{tabular}

Fonte: Elaborado pelos autores.

\section{Conclusão}

Durante o transcorrer deste trabalho, pôde ser evidenciado, nas organizações estudadas, que a questão da cultura institucional é um forte componente na mudança a ser operada. Novos patamares no desenvolvimento e na utilização compartilhada de equipamentos devem passar por mudanças significativas na individualização dos laboratórios e na compreensão da real necessidade do trabalho compartilhado. Essa mesma questão é comum no histórico de consolidação de algumas estruturas centralizadas de compartilhamento de equipamentos. Apesar do descrédito inicial muitas barreiras foram transpostas, e tem prevalecido a vitória do coletivo sobre o individual. No Rio de Janeiro, ficou evidenciada a dificuldade de operar algumas mudanças devido à cultura institucional, mas também pôde ser observado nos discursos de alguns o mesmo sentimento que disparou muitas transformações do uso individual para o coletivo.

No mundo atual, a percepção do tempo parece ter mudado e com ela a necessidade de respostas mais rápidas às demandas geradas. Em relação ao tema aqui discutido, esta velocidade ficou evidenciada com o lançamento de equipamentos de alto valor agregado, complexos e necessários ao desenvolvimento de novas metodologias. Nesse sentido as instituições investigadas exemplificam que em seu parque tecnológico existem modelos de equipamentos comparáveis a qualquer instituição internacional, de reconhecido mérito científico $^{16}$. Contudo, vários fatores navegam na contramão desta evolução, retardando os tão almejados resultados. Na administração pública, os mecanismos lentos e burocráticos de aquisição e contratação de serviços são totalmente antagônicos ao ambiente atual de desenvolvimento tecnológico, e ficam evidentes os entraves significativos que representam para as instituições deste estudo i,27-19. $^{\text {. }}$ 
O principal desafio encontrado foi a contratação e retenção de pessoas capacitadas e necessárias ${ }^{3}$, em parte dificultada pelos mesmos mecanismos lentos e burocráticos que aparecem em outros segmentos. No caso, a contratação representada pelos concursos públicos de difícil execução legal dificulta o pleno funcionamento de alguns locais; também a aquisição de insumos e peças de reposição fica dificultada pelos processos licitatórios públicos, causando sérios problemas à execução das análises. Os prazos de entrega extremamente longos de insumos e peças não condiz com a rotina de produtividade de análise proposta, e dificulta o planejamento das aquisições. Estes fatos ficaram evidenciados pela paralisação de diversos equipamentos, em vários dos laboratórios visitados. No Rio de Janeiro, ficou constatada que a grande variedade de equipamentos importados enfrenta problemas básicos de manutenção, com defeitos que impedem o correto funcionamento e a dificuldade de reposição de peças que afetam todo o processo da cadeia de pesquisa, significando a paralisação de ensaios, atraso de resultados e de trabalhos acadêmicos assim como das publicações. Para a inovação, esse tempo é fundamental. Há o desperdício de capacitação no caso de equipamentos que contam com pessoal já vinculado, mas de forma precária. Adicionalmente, foi observada a falta de contratos de manutenção para alguns equipamentos, o que contribui para a diminuição da sua vida útil. A gestão de equipamentos passou a desempenhar um papel preponderante no planejamento e implementação de rotinas de manutenção preventivas e corretivas necessárias a um parque de equipamentos. É urgente um olhar mais atento em relação ao enfrentamento desta questão e a consideração de uma gestão de equipamentos mais eficaz ${ }^{15}$ que estabeleça políticas e programas mais abrangentes de manutenção. Muitos problemas que foram evidenciados poderiam ser sanados se fossem tratados pró ativamente ${ }^{27}$ com a manutenção preventiva, uma política do sistema da qualidade ainda pouco implementada. Outra possível solução seria o fortalecimento de uma unidade de manutenção institucional que ampliasse a oferta do serviço, conforme um dos laboratórios já elaborou com o reconhecimento pelo sistema da qualidade nacional: a acreditação de calibrações.

Pode ser constatado que o conhecimento mais profundo do funcionamento dos equipamentos e as altas qualificações do quadro de funcionários aliados ao relacionamento estabelecido com fabricantes também podem significar arranjos excepcionais nesta questão. Muitos laboratórios, pelo peso do nome institucional que carregam, podem se tornar vitrines para o lançamento de novas metodologias despertando o interesse de negociação de muitas empresas fabricantes. A mesma opção de centralização poderia ser considerada para a realização da importação, treinando e capacitando pessoas para a realização do processo ponta a ponta, possibilitando a aquisição de insumos e equipamento com maior agilidade e otimização de recursos. O processo licitatório, pela ausência de competitividade, oferta de serviço ou outros aspectos legais dificulta o cumprimento das necessidades.

Outro ponto a ser destacado e que é citado repetidamente refere-se à cobrança de taxas que é realizada pelas instituições de São Paulo, que resolvem as questões principais relativas ao custeio, como contratação de mão de obra em algumas unidades, insumos, contratos de manutenção e qualificação e outras despesas menores $^{35}$. Nesse ponto, como sugestão para outros estudos, os possíveis mecanismos utilizados por estas unidades e os caminhos necessários para sua implementação devem ser verificados, uma vez que as instituições que os realizam também são públicas. Não foram avaliadas estas questões com o aprofundamento necessário, mas durante a execução deste trabalho foi observado o grande interesse despertado em alguns quando se fala do ressarcimento dos serviços prestados como forma de sustentação operacional. No Rio de Janeiro, ficou evidenciado um desconhecimento sobre a questão e os possíveis mecanismos de cobrança e aplicação dos recursos específicos. Nas unidades de São Paulo, em geral, ficou evidenciado um conhecimento sobre os aspectos legais e os mecanismos alternativos de cobrança e constituição dos Fundos de Operações para cobertura dos principais gastos, que possibilitam melhores soluções frente aos problemas relativos ao prazo do processo licitatório. Essa questão evidenciou uma grande diferença no nível organizacional alcançado pelas estruturas de um Estado para o outro, caracterizando um maior profissionalismo 
na entrega dos resultados. Voltando à questão das taxas, fica evidenciada a questão de como o usuário pode ser cobrado de forma justa e eficiente 4 ; no depoimento de uma unidade de São Paulo, evidenciou-se a preocupação com o cálculo e cobertura de gastos. Nesse sentido, Butler e Williams ${ }^{42}$ demonstram que eficiência e "justiça” na alocação de custos não são considerações necessariamente opostas e podem ser equacionadas. Por outro lado, Angeletti ${ }^{16}$ cita que a imposição de taxas muito altas pode constituir uma barreira à utilização de equipamentos por novos pesquisadores e também aponta que a cobrança excessiva e a imposição e operação de laboratórios de pesquisa como negócio pode ser caracterizada como falta de visão intelectual e científica, como evidenciado na preocupação de um discurso de São Paulo.

Na gestão diária vale ressaltar que muitas atividades necessitam ser planejadas, controladas e melhoradas continuamente. Nesse sentido, várias ferramentas de gestão podem ser adotadas ${ }^{25}$. Já é sabido que alguns pesquisadores não consideram estas funções como pertencentes ao seu âmbito de trabalho, apesar de muitos já reconhecerem a necessidade de uma gestão qualificada como apoio as suas operações.

\section{Referências}

1. Cassiolato JA. Economia do Conhecimento e as Novas Políticas Industriais e Tecnológicas. In: Albagli S, Lastres H.(Org). Informação e Globalização na Era do Conhecimento. 1 ed, Rio de Janeiro: Editora Campus; 1999.

2. Meneghelli L. O ambiente das organizações na era da globalização. [Internet] Instituto Catarinense de Pós-Graduação; 2011- [citado em 2015 jun 25] Disponível em: http://www.posuniasselvi.com.br/artigos/ rev01-03.pdf

3. Castells M. A Sociedade em Rede: a Era da Informação. Economia, Sociedade e Cultura. 10a ed. Lisboa: Fundação Calouste Gulbenkian; 2002.

4. Guimera R, Brian U, Spiro J, Nunes L. Team Assembly Mechanisms Determine Collaboration Network Structure and Team Performance. Science. 2005; 308: 697.

5. Katz J, Martin B. What is research collaboration? Research Policy.1997; 26(1):1-18.

6. Shrum W, Genuth J, Champalov J. Structures of Scientific Collaboration. Cambridge: The MIT Press; 2007.

7. Slaughter C. A bright but demanding future for Core facilities. Journal of Biomolecular Techniques. 2005; 16(2):167-169.

8. Haley R. Institutional Management of Core Facilities during Challenging Financial Times. Journal of Biomolecular Techniques. 2011; 22(4):127-130.

9. Hockberger P, Meyn S, Auger J. et al. Best Practices for Core Facilities: handling External Customers. Journal of Biomolecular Techniques. 2013; 24(2): 87-97.

10. Teixeira M, Filipecki A. A dinâmica da organização da pesquisa em biomedicina no Brasil: anatomia de uma experiência recente na Fundação Oswaldo Cruz. R. Eletr. de Com. Inf. Inov. Saúde.[Internet] 2009 Junho [citado em 2013 mar 23]; 9;3(2):47-72. Disponível em: http://www.reciis.icict.fiocruz.br/index. php/reciis/article/view/812

11. Ivanetich K, Niece R. Rohde L, Fowler E, Hayes T. Biotechnology core facilities: trends and update. FASEB Journal .1993; 7(12):1109-1114.

12. Zucker L, Darby R, Armstrong J. Intellectual Capital and the Firm: the Technology of Geographically Localized Knowledge Spillovers. Economic Inquiry. 1998; 36(1):65-86.

13. Wood K, Hachey D. Organization, management and operation of contemporary academic mass spectrometry service facilities. Journal of Mass Spectrometry. 2000; 35:1157-1164.

14. Aggeri F, Le Masson $P$ et al. Technological platforms in the life sciences. ERIEP. 2010 Jul 22;1:1-42.

15. Donas M. A Gestão da Manutenção de Equipamentos em uma Instituição Pública de C\&T em Saúde. [tese]. Rio de Janeiro. Escola Nacional de Saúde Pública, Fundação Oswaldo Cruz, 2004.

16. Angeletti RH, Bonewald LF, Jongh $\mathrm{K}$, Niece R, Rush J, Stults J. Research technologies: fulfilling the promise. FASEB Journal. 1999;13:595-601. 
17. Farber G, Weiss L. Core facilities: maximizing the return on investment. Science Translational Medicine. 2011; 3(95):1-3.

18. Haley R. A framework for managing core facilities within the research enterprise. Journal of Biomolecular Techniques. 2009; 20: 226-230.

19. Andereggen S, Zollera E, Boutellier R. Sharing research equipment to bridge intraorganization at boundaries: the cases of Novartis and ETH Zurich: shared equipment arrangements can help overcome organizational barriers that impede knowledge sharing. Research-Technology Management. 2013; 56(1): p. 49.

20. Langford C, Clayman P, Williams A. Pathways of knowledge flow between University researchers and users. THECIS The Centre of Innovation; University of Calgary. 2008.

21. Wood K, Hachey D. Organization, management and operation of contemporary academic mass spectrometry service facilities. Journal of Mass Spectrometry. 2000; 35:1157-1164.

22. Souza RA, Savignon Marinho, D, Brum APO, Morel, CM. Multi-user equipment, core facilities and technological platforms: the evolution of organizational strategies for translational health research. $\mathrm{R}$. Eletr. de Com. Inf. Inov. Saúde [Internet]. 2012 set [citado em 2013 mar 18];6(3) Disponível em: http:// www.reciis.icict.fiocruz.br/index.php/reciis/article/view/511/1158.

23. Colenci A, Neto M. O trabalho em equipe como diferencial competitivo na Organização: reflexos na universidade. Escola de Engenharia de São Carlos - Universidade de São Paulo, [Internet]:1999. [citado em fev. 2013]. Disponível em: http://abepro.org.br/biblioteca/ENEGEP A0619.pdf

24. Zolotov A. Instrument sharing centers. Journal of Analytical Chemistry. 2001; 56(3): 199.

25. Coulter C. Research Instrumental Sharing: continued availability of advanced instruments must evolve sharing: how are instruments shared? Science.1978 Aug 04;201(4354):415-20.

26. De Maggio S. Running and setting up a confocal microscope core facility. Cell Biological Applications of Confocal Microscopy. Methods in Cell Biology. 2002;70(14):475-485.

27. Mangematin V, Peerbaye A. Life Science Large Scale Research Facilities: what are the effects of technology transfer dynamics. EGOS Conference; França: Universitè Pierre Mendès; 2003.

28. Grey C. Um Livro Bom, Pequeno e Acessível sobre Estudos organizacionais. 2 ed, Bookman; 2012.

29. Teixeira M, Filipecki A. O uso de plataformas tecnológicas e suas implicações no modo de organização da pesquisa na área de biomedicina: análise preliminar da experiência da Fiocruz. R. Eletr. de Com. Inf. Inov. Saúde [Internet] 2011 mar [citado em 2013 mar 18]; 5(1):100-07. Disponível em: http://www. reciis.icict.fiocruz.br/index.php/reciis/article/view/524/1169.

30. Merz M, Biniok P. How Technological Platforms Reconfigure Science-Industry Relations: the Case of Micro and Nanotechnology. Minerva. 2010; 48(2):105-124.

31. Robinson D, Rip A, Mangematin V. Technological agglomeration and the emergence of clusters and networks in nanotechnology. Research Policy. 2007; 36(6): 871-879.

32. Gibbs G, Clark S, Quinn J, Gleeson M. Cost (non)-recovery by platform technology facilities in the Bio21 Cluster. Journal of Biomolecular Techniques. 2010; 21(1):29-34.

33. Lilley K, Deery M, Gatto L. Challenges for proteomics core facilities. Proteomics. 2011; 11(6):1017-1025.

34. Wiebe GJ, Pershad R, Escobar H, Hawes, JW, Hunter, T, Jackson-Machilski, E, et al. DNA Sequencing Research Group (DSRG) 2003: a general survey of core DNA sequencing facilities. J Biomol Tech. 2003 Sep;14(3):231-235.

35. Williams KR, Niece RL, Atherton D, Fowler AV, Kutny R, Smith AJ. The size, operation, and technical capabilities of protein and nucleic acid core facilities. FASEB J. 1988 Dec;2(15):3124-30.

36. Marshall I Jr, Rocha A, Mota E, Quintella O. Gestão da qualidade e processos. Rio de Janeiro: Editora FGV, 2012.

37. Champy J. Preparando-se para a mudança organizacional. In: Hesselbein et al. (Orgs). A Organização do Futuro: como preparar hoje as empresas de amanhã. 2ed. Peter Drucker Foundation; p.25-31, 1997.

38. Bardin L. Análise de conteúdo. São Paulo; Edições 70; 2011. 
39. Trogards J. Issues in the Management of a Core Imaging Facility. Magazine LabManager. 2006; 1(4):1116.

40. Loo R, Nicolet C, Niece R. et al. Association of Biomolecular Resource Facilities Survey: service Laboratory Funding. Journal of Biomolecular Techniques. 2009; 20(3): 180-185.

41. Vanderbilt University Medical Center Office of Research. Guidelines for research shared resources and core facilities: cost center operations [Internet]. Nashville, 2008 [citado em 2013 jun 3]. Disponível em: https://medschool.vanderbilt.edu/oor/files/oor/public files/2015 VUMC Core Guidelines July\%202015. pdf

42. Butler $\mathrm{M}$, Williams $\mathrm{H}$. Fairness versus efficiency in charging for the use of common facilities. Journal of the Operational Research Society. 2002; 53(12):1324-1329. 